\title{
PERDAS DE FRUTAS FRESCAS NO COMÉRCIO VAREJISTA DE MINEIROS-GO: UM ESTUDO DE CASO ${ }^{1}$
}

\author{
MAURO BRASIL DIAS TOFANELLI², MARILAINE DE SÁ FERNANDES 3 , \\ OSCAR BARBOSA MARTINS FILHO ${ }^{4}$, NÚBIA SOUSA CARRIJO ${ }^{4}$
}

RESUMO - O presente trabalho teve como objetivo realizar levantamento das perdas de frutas frescas nos mercados varejistas do município de Mineiros-GO, bem como suas causas e providências a serem tomadas. Para isso, foram realizadas pesquisas mediante visitação aos equipamentos varejistas (supermercados, quitandas/sacolões e feira livre) para aplicação de questionário. Os resultados demonstraram que, semanalmente, são perdidos 3,2\% do volume de frutas comercializado em Mineiros e que os supermercados, por serem os principais mercados varejistas, são predominantes no volume de perdas. Os mercados varejistas citaram o armazenamento inadequado (falta de refrigeração) e as más condições de transporte (rodovias sob condições ruins de conservação) como as principais causas das perdas de frutas frescas. O controle de estoque, a educação do consumidor final e a melhoria da qualidade das frutas são medidas prioritárias a serem tomadas conforme a rede varejista. Conclui-se que os mercados varejistas de Mineiros precisam desenvolver ações mais enérgicas e apresentar atitudes a fim de diminuir as perdas dos produtos frutícolas.

Termos para indexação: Desperdício, mercado de frutas, varejo, comercialização.

\section{FRESH FRUIT LOSSES AT RETAIL MARKETS IN MINEIROS, \\ STATE OF GOIÁS, BRAZIL}

ABSTRACT - The present work had as objective to carry through survey the losses of fresh fruits in the retail markets of the city of Mineiros-GO, as well as its causes and steps to be taken. For this research, visitation to the retail markets (supermarkets, groceries stores and street market) for an application of a questionnaire was realized. The results showed that $3.2 \%$ of the volume of fruits commercialized in Mineiros are lost weekly and that the supermarkets, being the main retail markets, are predominant in the volume of losses. The retail markets had cited the inadequate storage (refrigeration lack) and the bad conditions of transport (highways under bad conditions of conservation) as the main causes of the losses of fresh fruits. Supplying control, the education of the consumer, and fruit quality improvement are priority measures to be taken by the retail markets. It was concluded that the retail markets of Mineiros need to develop more energetic actions and to be taken attitudes in order to control the losses of the fruit products.

Index terms: Waste, fruit market, retail market, commercialization.

\section{INTRODUÇÃO}

A escassez de alimentos em várias partes do planeta seria menos preocupante se os excessivos índices de desperdício fossem diminuídos. O combate à fome é a principal missão entre dezoito metas a serem atingidas neste milênio, sendo oito dos objetivos a serem alcançados até 2015, conforme ficou estabelecido pela Declaração do Milênio - um documento referendado em setembro de 2000, em Nova York, durante a Cúpula do Milênio, por 191 nações, a qual estabelece o compromisso de todos os países-membro da Organização das Nações Unidas (ONU) com o cumprimento das metas estabelecidas (Gonçalves, 2005).

Uma das causas para os altos volumes de frutas desperdiçados no Brasil é a carência de estudos mercadológicos de todo o complexo comercial dos produtos, que poderiam fornecer valiosas informações e contribuir para atenuar as perdas. Foi o que consideraram Silva et al. (2003) quando mencionaram ser de grande importância a transparência nas relações entre os agentes da produção, agroindústria, atacado, varejo e consumidor final; onde informações de cada elo sejam do conhecimento de todos para evitar, por exemplo, as perdas pós-colheita dos produtos agrícolas, o que pode estar refletindo em um grau de desarticulação nestes sistemas.

Conforme Fagundes e Yamanishi (2002), o Ministério da Agricultura do Abastecimento e Reforma Agrária considera que o Brasil perde, anualmente, mais de 1 bilhão de dólares de frutas e hortaliças, sendo as porcentagens estimadas de perdas de mamão em 23,7\%. Esses autores ainda mencionaram que, apesar do grande volume de produtos no mercado interno, sua comercialização é limitada, pois esses são altamente perecíveis e manuseados sob condições ambientais que aceleram a perda de qualidade. Esses autores ainda afirmaram que as perdas estão relacionadas com o porte do estabelecimento comercial, geralmente supermercados, que trabalham com maior volume de produtos frutícolas ou até mesmo do manuseio inadequado dos

(Trabalho 172-06). Recebido:30-10-2006. Aceito para publicação em : 25-06-2007. Apoio Financ: Fimes

${ }^{2}$ Eng $^{\circ}$ Agrônomo, Prof. Adjunto, Doutor, ICA/Faculdades Integradas de Mineiros/Fimes. Endereço: Rua 22, s/n, Setor Aeroporto, Caixa Postal 104, CEP 75830-000, Mineiros-GO. Email: maurobrasil@fimes.edu.br

${ }^{3}$ Enga $^{a}$ Agrônoma, Profa. Assistente, Mestre, ICA/Faculdades Integradas de Mineiros/Fimes. Coordenadora do Instituto de Dados Estatísticos e de Pesquisas Sócio-econômicas - Indep/Fimes.

${ }^{4}$ Acadêmico do Curso de Engenharia Florestal, bolsista Indep/Fimes.

Rev. Bras. Frutic., Jaboticabal - SP, v. 29, n. 3, p. 513-517, Dezembro 2007 
frutos pelos funcionários ou pelos próprios consumidores.

Silva et al. (2003) demonstraram, em trabalho desenvolvido para avaliar as perdas de banana no município de Botucatu-SP, que a falta de controle na compra e venda dos produtos foi o maior causador nas quitandas/sacolões e feiras livres, e que é de suma importância ter conhecimento do estudo de comercialização, pois a organização mais eficiente da cadeia depende das características do produto e do mercado, e um dos fatores que contribui para uma postura cooperativa, é a transparência nas relações entre os elos de comercialização.

Para Bueno et al. (1999), conhecer os canais de comercialização do produto vegetal é fundamental para gerar informação que servirá de ferramenta para melhor organização do contexto, como saber entregar o produto no lugar adequado, no momento certo, na forma e quantidade desejadas, criando-se as utilidades de posse, lugar, tempo e forma. Fagundes \& Yamanishi (2002) também afirmaram que é de fundamental importância conhecer alguns fatores que contribuem para a formação do processo para que sejam adotadas técnicas que visem a melhorar o sistema de comercialização de produtos vegetais.

Os relatos existentes sobre perdas de frutas quase sempre ficam restritos a grandes centros urbanos referenciando-se sobre as Centrais de Abastecimentos (Ceasas), o que não fornece dados precisos da real situação do contexto mercadológico das distintas cidades brasileiras. Para o município de Mineiros, não é diferente, pois não há relatos sobre o volume de frutas desperdiçado no mercado varejista.

O presente estudo teve como objetivo realizar levantamento de informações sobre perdas de frutas e suas causas nos principais canais de comercialização em MineirosGO, fornecendo parâmetros e subsídios às ações de melhoria do setor.

\section{MATERIAL E MÉTODOS}

O trabalho foi desenvolvido em Mineiros, município localizado no sudoeste do Estado de Goiás, às margens da rodovia BR-364, a 108 km a leste do município de Jataí-GO, e a 90 km a oeste do município de Santa Rita do Araguaia-GO (divisa com o Estado do Mato Grosso), sendo as capitais estaduais mais próximas Goiânia-GO a 420 km e Cuiabá-MT a 500 km.

Mineiros possui uma população de 43.961 pessoas, conforme estimativa realizada para julho de 2005, do Instituto Brasileiro de Geografia e Estatística (IBGE, 2006), apresentando como atividade principal a agropecuária baseada na exploração de culturas anuais, como soja e milho, e da pecuária de corte e leite.

Os estabelecimentos responsáveis pela comercialização de produtos hortifrutícolas em Mineiros resumem-se em supermercados, quitandas/sacolões e feiralivre, seguindo classificação proposta por Barros et al. (1978), citados por Silva et al. (2003). O universo adotado para estudo foi constituído por onze equipamentos varejistas, sendo oito supermercados de médio a pequeno portes, duas quitandas (conhecidas localmente como "frutarias") e uma feiralivre (única do município e com funcionamento semanal nas manhãs de domingo). Para a escolha dos mercados, utilizou-se, como critério, a representatividade (importância, porte e popularidade) de cada estabelecimento comercial, abrangendo os principais pontos (canais) de comercialização de frutas frescas ao consumidor final.

De dezembro de 2005 a janeiro de 2006, foram realizadas pesquisas nos equipamentos varejistas mediante visitação in loco para aplicação de questionário constituído por perguntas direcionadas. As entrevistas foram realizadas diretamente com os encarregados do setor de hortifrutícolas nos supermercados, com os proprietários das quitandas/sacolões e com todos os feirantes das bancas ou barracas de venda da feiralivre que comercializavam frutas. O questionário foi aplicado pela equipe de entrevistadores do Instituto de Dados Estatísticos e de Pesquisas Sócioeconômica (Indep) pertencente às Faculdades Integradas de Mineiros, mantidas pela Fundação Integrada Municipal de Ensino Superior (Fimes) de Mineiros-GO.

As perguntas que constituíram o questionário, foram elaboradas de maneira que os entrevistados fornecessem respostas subjetivas e objetivas, conforme o propósito de cada questão e as realidades de cada equipamento varejista para obter as seguintes informações: a) As dez maiores perdas semanais, em volume, das principais frutas comercializadas no equipamento, sendo considerada como perda a fruta que não atingiu o consumidor final e não teve seu valor agregado; b) As dez principais frutas comercializadas, em volume; c) O principal motivo causador das perdas de frutas, e d) As principais micro e macroprovidências que poderiam ser tomadas para diminuir as perdas de frutas no equipamento varejista. Os resultados obtidos foram tabulados e organizados em planilhas processadas pelo Indep/Fimes.

\section{RESULTADOS E DISCUSSÃO}

Embasado no panorama geral, pode-se considerar que o mercado varejista de Mineiros proporciona baixos índices de desperdícios de seus produtos frutícolas, pois apenas 3,2\% das frutas frescas são perdidas e não são consumidas (Tabela 1). Para Gonçalves (2005), 10\% das frutas são perdidas entre a rede varejista e os consumidores finais na cidade do Rio de JaneiroRJ. Ramos et al. (2002) também diagnosticaram perdas de frutas mais elevadas no mercado varejista do município de Lavras-MG, concentrando-se entre 11,0 e $15,0 \%$. Por outro lado, o desperdício de frutas no varejo mineirense foi maior que o praticado na CeasaGO (Goiânia-GO), pois, conforme Diário da Manhã (2006), é onde ocorrem perdas em torno de $1 \%$ do volume de hortifrutícolas que circulam neste atacado. Em Mineiros, por ser um mercado de frutas menos movimentado em conseqüência de sua menor população quando comparado aos grandes centros urbanos, ficam facilitadas as ações para inibir as demasiadas perdas neste 
nível de comercialização, como melhor controle de estoques, evitando-se compras em excesso, abastecimento oriundo praticamente de um mesmo fornecedor, e duas vezes por semana (Fernandes, 2006), menor diversificação de produtos frutícolas e outras características típicas de pequenos mercados que contribuíram para assegurar o baixo índice de desperdícios.

$\mathrm{Na}$ feiralivre, observou-se porcentagem média de perdas mais acentuada $(5,0 \%)$, seguida pelos supermercados $(3,3 \%) \mathrm{e}$ quitandas (2,7\%) (Tabela 1). A feiralivre de Mineiros não é o principal canal de distribuição de frutas ao consumidor final e oferece poucas variedades de produtos frutícolas ao consumidor final. Nestas condições, o abacaxi foi citado como fruta em que se registraram perdas, o que sujeitou este equipamento ao maior índice; porém, há de se enaltecer o total aproveitamento das outras frutas neste varejo, como, por exemplo, os citros (Fernandes, 2006). Já as quitandas apresentaram o índice menos acentuado, o que pode ser explicado pelo melhor tratamento que as frutas recebem neste tipo de varejista. Silva et al. (2003) afirmaram que as quitandas (sacolões) são estabelecimentos comerciais especializados em hortifrutigranjeiros que oferecem produtos de qualidade e em diversidade. A porcentagem de perdas nos supermercados demonstra que estes equipamentos estão especializando-se como canal de distribuição de frutas diretas ao consumidor final, pois apresentaram apenas $3,3 \%$ de perdas.

Banana, mamão, laranja e abacaxi destacaram-se praticamente em todos os parâmetros avaliados. Observou-se expressivo volume de perdas semanais para laranja, o que pode ser explicado pelo alto volume comercializado; por outro lado, para esta fruta, registrou-se baixa porcentagem de perdas, proporcional ao volume comercializado (PPV), apenas 1,0\% (Tabela 1). Isto é explicado devido ao menor índice de perecibilidade e à resistência ao excessivo manuseio que as frutas cítricas apresentam (Bueno et al., 1999). Por outro lado, a alta perecibilidade pode explicar os incrementos nos índices de perdas de banana, mamão e abacaxi. As porcentagens de perdas destas frutas foram similares às obtidos em outros trabalhos, como o desenvolvido por Rangel et al. (2003), que demonstraram desperdícios de mamão na ordem de 5\% nos supermercados envolvidos na pesquisa; e o realizado por Silva et al. (2003), onde relataram perdas médias de $11,1 \%$ de banana nos equipamentos varejistas entrevistados.

Os menores volumes de perdas foram registrados para uva, pêra, ameixa, nectarina e pêssego, devido aos baixos volumes comercializados, porém obtiveram tendência a maiores índices de perdas isoladamente, como pêssego e ameixa, que demonstraram 50,0 e 14,7\% de perdas, respectivamente (Tabela 1). Fernandes et al. (2006) demonstraram que essas frutas normalmente são vendidas a preços mais elevados e isso pode ter contribuído para o maior volume de sobras nas prateleiras, que resultaram em maiores perdas. Rangel et al. (2003) consideraram que a diminuição das perdas de mamão no Distrito Federal poderia ser obtida mediante redução do preço do produto ao consumidor final. Silva et al. (2003) demonstraram que o preço é o principal motivo que influencia nas perdas de banana nos supermercados de Botucatu-SP. Já Gonçalves (2005) relatarou que uma das principais conseqüências do desperdício são os preços mais altos para o consumidor, nos quais estão embutidos os prejuízos, a fim de compensar as perdas.

Os supermercados, que são os principais canais de comercialização de frutas ao consumidor em Mineiro, foram majoritários no quesito perda de frutas, pois calculou-se participarem com $72 \%$ do total geral de desperdícios semanais desses alimentos (Tabela 1). Neste tocante, o baixo índice de 4\% para feiralivre é explicado pela pouca variedade e quantidade de frutas comercializadas por esse canal de distribuição (Fernandes et al., 2006).

Para os varejistas mineirenses, o grande fator causador das perdas de frutas frescas nos mercados locais são as condições de armazenamento dos seus estabelecimentos, principalmente quanto à falta de câmara refrigerada, pois a presente pesquisa revelou que $36,4 \%$ dos varejistas citaram este fator como o principal motivo para as perdas obtidas nos equipamentos (Tabela 2). Os resultados demonstraram também que $18,2 \%$ dos varejistas entrevistados citaram as más condições das rodovias brasileiras, mais especificamente as do Estado de Goiás, também como fator causador das perdas de frutas. Outros fatores, como baixa qualidade das frutas, compra excessiva, condições ambientais, estado de maturação das frutas e manipulação inadequada do consumidor final, também foram citados $(9,1 \%)$. Esses resultados são importantes para sugerir melhor estruturação dos mercados varejistas, como, por exemplo, instalação de câmara refrigeradora para prolongar a conservação das frutas, além de servirem de instrumento para investidas perante os órgãos públicos para buscar apoio ao setor. É ainda importante ressaltar que os prejuízos ocasionados pelas perdas podem justificar investimentos em sistema de refrigeração para o equipamento varejista.

Rangel et al. (2003) estudaram o perfil do mercado varejista e do consumidor de mamão no Distrito Federal e demonstraram que os mercados expõem os frutos nas prateleiras sem refrigeração e que isso contribui para as perdas desta fruta. Estes autores ainda ressaltaram a importância de se realizarem futuros estudos para avaliar a relação entre os custos de refrigeração do mamão no transporte, armazenamento e comercialização, e a redução das perdas com a prática de refrigeração.

Os equipamentos varejistas precisam ter atitudes para combater as perdas no comércio de frutas frescas, porém é necessário saber quais são as prioridades para que as ações internas (microprovidências) e externas (macroprovidências) sejam as mais eficientes e abrangentes possíveis para o específico canal de comercialização como um todo. Neste tocante, para o mercado mineirense de frutas in natura, o controle de estoque é a principal providência a ser tomada para diminuir o volume de perdas (Tabela 3), ou seja, saber quanto e quando comprar são informações imprescindíveis para evitar sobras nas prateleiras. Silva et al. (2003), estudando as perdas de banana no mercado varejista de Botucatu$\mathrm{SP}$, afirmaram que mudanças pontuais nos mercados, como 
gerenciamento de estoque e exposição da fruta, podem ocasionar a redução das perdas.

Dentre as macroprovidências citadas como prioridades pelos mercados, a educação do consumidor final e a melhoria da qualidade das frutas são as principais medidas a serem providenciadas no contexto mais amplo da comercialização. Fagundes e Yamanisghi (2002) demonstraram que o manuseio inadequado pelos clientes foi uma das principais causas de perdas na comercialização de mamão no Distrito Federal e que o consumidor deve evitar causar danos ao produto que está adquirindo, sejam estes provocados por compressão, arranhões ou pela queda. Fagundes e Yamanishi (2001) sugeriram que a melhoria da qualidade de fruto e o aumento da eficiência na produção e na comercialização reduzem perdas e custos, aumentando as receitas. Ramos et al. (2002) afirmaram que as principais perdas de frutas no comércio de frutas em Lavras-MG, foram devidas às condições climáticas no estabelecimento e ao manuseio do consumidor.
Apesar de o mercado varejista de Mineiros não ter apresentado excessivos índices de perdas de frutas frescas, é importante lembrar que o presente estudo foi desenvolvido em apenas um segmento de comercialização e que os demais elos deste complexo não foram considerados, sendo as informações aqui apresentadas essenciais para servirem de parâmetros para as ações e tomadas de decisões em busca das soluções dos problemas.

TABELA 1 - Perdas semanais de frutas frescas comercializadas no município de Mineiros-GO. ICA/ Fimes, Mineiros-GO.

\begin{tabular}{|c|c|c|c|c|c|c|c|c|c|c|c|c|c|c|c|c|}
\hline \multirow[t]{2}{*}{ Fruta } & \multicolumn{4}{|c|}{ Supermercados } & \multicolumn{4}{|c|}{ Quitandas/Sacolões } & \multicolumn{4}{|c|}{ Feira livre } & \multicolumn{4}{|c|}{\begin{tabular}{|l} 
Total do Varejo \\
\end{tabular}} \\
\hline & $\begin{array}{c}\text { VP } \\
(\mathrm{kg})\end{array}$ & $\begin{array}{c}\text { PRP } \\
(\%)\end{array}$ & $\begin{array}{c}\mathrm{VC} \\
(\mathrm{kg})\end{array}$ & $\begin{array}{l}\text { PPV } \\
(\%)\end{array}$ & $\begin{array}{c}\text { VP } \\
(\mathrm{kg})\end{array}$ & $\begin{array}{c}\text { PRP } \\
(\%)\end{array}$ & $\begin{array}{c}\mathrm{VC} \\
(\mathrm{kg})\end{array}$ & $\begin{array}{l}\text { PPV } \\
(\%)\end{array}$ & $\begin{array}{c}\text { VP } \\
(\mathrm{kg})\end{array}$ & $\begin{array}{l}\text { PRP } \\
(\%)\end{array}$ & $\begin{array}{c}\text { VC } \\
(\mathrm{kg})\end{array}$ & $\begin{array}{l}\text { PPV } \\
(\%)\end{array}$ & $\begin{array}{c}\text { VP } \\
(\mathrm{kg})\end{array}$ & $\begin{array}{c}\text { PRP } \\
(\%)\end{array}$ & $\begin{array}{c}\mathrm{VC} \\
(\mathbf{k g})\end{array}$ & $\begin{array}{l}\text { PPV } \\
(\%)\end{array}$ \\
\hline Banana & 132,2 & 39,2 & $1.546,0$ & 8,6 & & & & & & & & & 132,2 & 28,2 & $1.546,0$ & 8,6 \\
\hline Mamão & 37,0 & 11,0 & 443,0 & 8,4 & 60,0 & 53,0 & 900,0 & 6,7 & & & & & 97,0 & 20,7 & $1.343,0$ & 6,6 \\
\hline Laranja & 34,1 & 10,1 & $4.746,0$ & 0,7 & 37,5 & 26,5 & $2.350,0$ & 1,6 & & & & & 71,6 & 15,3 & $7.096,0$ & 1,0 \\
\hline Abacaxi & 52,5 & 15,6 & 810,0 & 6,5 & & & & & 18,8 & 100,0 & 375,0 & 5,0 & 71,3 & 15,2 & $1.185,0$ & 6,0 \\
\hline Maçã & 47,2 & 14,0 & $2.122,0$ & 2,2 & 9,0 & 16,5 & 720,0 & 1,3 & & & & & 56,2 & 12,0 & $2.842,0$ & 2,0 \\
\hline Uva & 13,6 & 4,0 & 370,0 & 3,7 & 6,0 & 4,0 & 135,0 & 4,4 & & & & & 19,6 & 4,2 & 505,0 & 3,8 \\
\hline Pêra & 8,0 & 2,4 & 204,0 & 3,9 & & & & & & & & & 8,0 & 1,7 & 204,0 & 3,9 \\
\hline Ameixa & 5,0 & 1,5 & 34,0 & 14,7 & & & & & & & & & 5,0 & 1,1 & 34,0 & 14,7 \\
\hline Nectarina & 4,0 & 1,2 & 56,0 & 7,1 & & & & & & & & & 4,0 & 0,9 & 56,0 & 7,1 \\
\hline Pêssego & 4,0 & 1,2 & 8,0 & 50,0 & & & & & & & & & 4,0 & 0,9 & 8,0 & 50,0 \\
\hline TOTAL & 337,6 & 100 & $10.339,0$ & & 112,5 & 100 & $4.105,0$ & & 18,8 & 100 & 375,0 & & 468,9 & 100 & $14.819,0$ & \\
\hline PPVCE \% & & &, 3 & & & & 2,7 & & & 5,0 & & & & 3,2 & & \\
\hline PPVTGP \% & & & 2,0 & & & & 4,0 & & & 4,0 & & & & 100 & & \\
\hline
\end{tabular}

VP - Volume de Perdas semanais da fruta no equipamento em kg; PRP - Porcentagem Relativa de Perdas; VC - Volume Comercializado da fruta semanalmente no equipamento; PPV - Porcentagem de Perdas em relação ao VC da fruta (PPV = VP x 100/VC); PPVT - Porcentagem de Perdas em relação ao Volume Comercializado do Equipamento (PPVT = VP total x 100/VCtotal); PPVTG - Porcentagem de Perdas em relação ao Volume Total Geral de Perdas de frutas $($ PPVTGP $=$ VP equipamento $\times 100 /$ VP total varejo).

TABELA 2- Principais motivos causadores das perdas das principais frutas frescas comercializadas em Mineiros-GO, conforme a rede varejista local. ICA/ Fimes, Mineiros-GO.

\begin{tabular}{lccccc}
\hline Motivo & \multicolumn{3}{c}{ \% Relativa } & Resposta & \% Média \\
\cline { 2 - 4 } & Supermercados & Quitandas & Feira livre & Total do Varejo \\
\hline Armazenamento inadequado & 50,0 & 0,0 & 0,0 & 36,4 \\
Más condições de transporte & 25,0 & 0,0 & 0,0 & 18,2 \\
Baixa qualidade das frutas & 0,0 & 0,0 & 100,0 & 9,1 \\
Compra excessiva & 0,0 & 50,0 & 0,0 & 9,1 \\
Condições ambientais & 12,5 & 0,0 & 0,0 & 9,1 \\
Frutas não chegam frescas nos mercados & 12,5 & 0,0 & 0,0 & 9,1 \\
Manipulação excessiva do consumidor & 0,0 & 50,0 & 0,0 & 9,1 \\
\hline
\end{tabular}

TABELA 3 - Micro e macroprovidências para diminuir as perdas das principais frutas frescas comercializadas em Mineiros-GO, conforme a rede varejista local. ICA/ Fimes, Mineiros-GO.

\begin{tabular}{|c|c|c|c|c|}
\hline \multirow[t]{2}{*}{ Providências } & \multicolumn{3}{|c|}{ \% Relativa-Resposta ${ }^{1}$} & \multirow{2}{*}{$\begin{array}{c}\text { \% Média } \\
\text { Total do Varejo }\end{array}$} \\
\hline & Supermercados & Quitandas & Feira livre & \\
\hline \multicolumn{5}{|l|}{ Micro } \\
\hline Controle de estoque & 57,1 & 66,7 & 0,0 & 50,0 \\
\hline Compra de frutas mais frescas & 14,3 & 0,0 & 0,0 & 10,0 \\
\hline Compra de frutas regionais & 14,3 & 0,0 & 0,0 & 10,0 \\
\hline Diminuição dos preços no varejo & 14,3 & 0,0 & 0,0 & 10,0 \\
\hline Melhora na estrutura das barracas & 0,0 & 0,0 & 100,0 & 10,0 \\
\hline Processamento das frutas & 0,0 & 33,3 & 0,0 & 10,0 \\
\hline \multicolumn{5}{|l|}{ Macro } \\
\hline Diminuição dos preços no atacado & 30,0 & 0,0 & 0,0 & 25,0 \\
\hline Educação do consumidor final & 20,0 & 100,0 & 0,0 & 25,0 \\
\hline Melhora da qualidade das frutas & 20,0 & 0,0 & 0,0 & 25,0 \\
\hline Fornecedores atacadistas mais próximos & 20,0 & 0,0 & 0,0 & 16,7 \\
\hline Melhora das condições das rodovias & 10,0 & 0,0 & 100,0 & 8,3 \\
\hline
\end{tabular}

r Respostas múltiplas.

${ }^{1}$ Respostas múltiplas. 


\section{CONCLUSÕES}

1-O índice de perdas de frutas em Mineiros é baixo (3,2\%).

2- Os supermercados, por serem os principais canais de comercialização de frutas frescas, devem priorizar o desenvolvimento de estratégias conjuntamente para atenuar a predominante participação $(72,0 \%)$ nas perdas dos produtos frutícolas.

3- Sugere-se aos mercados varejistas realizar maiores investimentos na estruturação dos estabelecimentos e agir energicamente frente à cadeia produtiva e aos diversos seguimentos privados e públicos em busca de melhoria e apoio ao setor, pois, conforme a rede varejista local, as principais causas das perdas são o armazenamento inadequado, as más condições de transporte e a baixa qualidade dos produtos. Só assim, será possível realizar melhor controle de estoque, fornecer preços mais acessíveis ao consumidor final, conscientizar o consumidor final e disponibilizar de fornecedores atacadistas mais próximos.

\section{REFERÊNCIAS}

BUENO, C.R; REIS, R.P.; SOUZA, M. de. Estudo mercadológico da sazonalidade de frutos cítricos ofertados no município de Lavras-MG. Ciência e Agrotecnologia, Lavras, v.23, n.4, p.813824, 1999.

DIÁRIO DA MANHÃ. Jornal Diário da Manhã. Goiânia, n.946, p.12, mar. 2006. Suplemento do Campo.

FAGUNDES, G.R.; YAMANISHI, O.K. Quantidade e preços da banana- 'prata' comercializada nas Ceasas do Distrito Federal, São Paulo, Belo Horizonte e Rio de Janeiro, no período de 1995 a 1999. Revista Brasileira de Fruticultura, Jaboticabal, v.23, n., p.593596, dez. 2001

FAGUNDES, G.R.; YAMANISHI, O.K. Estudo da comercialização do mamão em Brasília-DF. Revista Brasileira de Fruticultura, Jaboticabal, v.24, n.1, p.091-095, 2002.

FERNANDES, M. de S.; TOFANELLI, M.B.D.; CARRIJO, N.S.; MARTINS FILHO, O.B. Resultados do levantamento do volume comercializado e perdas de produtos hortifrutigranjeiros no mercado varejista de Mineiros-GO. Mineiros: Fimes/Indep, 2006. 81p. (Relatório de Pesquisa).

GONÇALVES, B.S. (Coord. e Ed.). O Compromisso das empresas com o combate ao desperdício de alimentos: banco de alimentos, colheita urbana e outras ações. São Paulo: Instituto Ethos, 2005. 80p.
INSTITUTO BRASILEIRO DE ECONOMIA. Economia e gestão: indicadores econômicos. Rio de Janeiro: IBRE/Fundação Getúlio Vargas. Disponível em: $<$ http://www2.fgv.br/dgd/asp/ index.asp > . Acesso em: 13 jun. 2006.

INSTITUTO BRASILEIRO DE GEOGRAFIA E ESTATÍSTICA. IBGE. Estimativas de população. Disponível em: $<\mathrm{ftp}: / /$ ftp.ibge.gov.br/Estimativas Projecoes Populacao Estimativas_2005/UF_Municipio.zip>. Acesso em: 13 jul. 2006.

RAMOS, J.D.; PIO, R.; MENDONÇA, V. Situação da fruticultura no município de Lavras-MG. Ciência e Agrotecnologia, Lavras, p.1594-1598, dez. 2002. Edição Especial

RANGEL, S.B.; FAGUNDES, G.R.; FALCÃO, T.C.C.; M. de S.M.; YAMANISHI, O.K. Perfil do mercado varejista e consumidor de mamão dos grupos 'solo' e 'formosa' do Distrito Federal-DF. Revista Brasileira de Fruticultura, Jaboticabal, v.25, n.1, p.8588. abr. 2003.

SILVA, C. de S.; PEROSA, J.M.Y.; RUA, P.S.; ABREU, C.L.M. de; PÂNTANO, S.C.; VIEIRA, C.R.Y.I., BRIZOLA, R.M. de O. Avaliação econômica das perdas de banana no mercado varejista: um estudo de caso. Revista Brasileira de Fruticultura, Jaboticabal, v.25, n.2, p229-234, ago. 2003. 